\title{
Pengaruh Pelatihan Komunikasi Interpersonal Terhadap Kohesivitas Kelompok pada Divisi Food and Beverage Product Hotel X Bintang 5 Yogyakarta
}

\author{
Ammy Novita Setiawati ${ }^{1}$, Bagus Riyono ${ }^{2}$ \\ ${ }^{1}$ Fakultas Psikologi dan Ilmu Sosial Budaya Universitas Islam Indonesia \\ e-mail: ${ }^{1}$ ammy031189@gmail.com
}

\begin{abstract}
Abstrak. Penelitian ini bertujuan untuk melihat efektifitas pelatihan komunikasi interpersonal terhadap kohesivitas kelompok dalam divisi food \& beverage product hotel $\mathrm{X}$ bintang 5 Yogyakarta. Materi dan desain pelatihan yang digunakan dalam penelitian ini disusun dengan menggunakan unsur-unsur komunikasi interpersonal menurut Devito (1989) yaitu: keterbukaan, sikap empati, sikap mendukung, sikap positif serta kesetaraan. Penelitian ini menggunakan metode eksperimen dengan desain penelitian untreated control group design with pretest and posttest. Responden terdiri dari 32 subjek yang dibagi menjadi dua kelompok, yaitu kelompok eksperimen dan kelompok kontrol. Pengukuran kohesivitas kelompok menggunakan skala kohesivitas kelompok yang disusun berdasarkan teori kohesivitas kelompok Widmeyer (Paola \& Carless, 2000) dalam 4 dimensi yaitu, yaitu integrasi kelompok tugas, integrasi kelompok sosial, ketertarikan individu kepada kelompok tugas, dan ketertarikan individu kepada kelompok sosial. Hasil analisis data dengan menggunakan wilcoxon t-test ditemukan perbedaan yang signifikan sebelum dan sesudah dilakukannnya pelatihan komunikasi interpersonaldengan nilai $\mathrm{z}=-3,519$ dan signifikansi $0,000(\mathrm{p}<0,05)$.
\end{abstract}

Kata Kunci: Pelatihan komunikasi interpersonal, kohesivitas kelompok

Abstract. This study aims to look at the effectiveness of the training of interpersonal communication on group cohesiveness in the division of food \& beverage product $X 5$ star hotel in Yogyakarta. The materials and design of training used in this study have been prepared using the elements of interpersonal communication according to DeVito (1989), namely: openness, empathy, being supportive, positive attitude and equality. This research used experimental research design untreated control group design with pretest and posttest. Respondents consisted of 32 subjects were divided into two groups: the experimental group and the control group. Measurement of group cohesiveness using group cohesiveness scale which is based on the theory of group cohesiveness Widmeyer (Paola \& Carless, 2000) in four dimensions, namely the integration of the task group, the integration of social groups, interest groups of individuals to the task, and the interest of the individual to the social group.The results of data analysis using Wilcoxon t-test found significant difference before, after and follow up after the perpetration of interpersonal communication training with a value of Chi Square $=5,200$ and 0,000 significance ( $p<$ $0,05)$.

Keywords: Training of interpersonal communication, group cohesiveness

Pada sebuah organisasi terdapat kelompok-kelompok kerja yang didalamnya terdapat individu-individu. Individu-individu tersebut memiliki kinerja atau performa masingmasing demi mencapai efektivitas kelompok. Keefektifan kelompok itu sendiri nantinya 
akan berpengaruh pada efektivitas organisasi. Gibson, Ivancevich, Donnelly, dan Konopaske (2003) memandang bahwa konsep keefektifan organisasi terdiri dari tiga perpektif, yaitu keefektifan individu, keefektifan kelompok, dan keefektifan organisasi. Ketiga hal tersebut saling berkaitan satu sama lain. Individu didalam sebuah kelompok memang harus menunjukkan performa terbaik dalam melakukan pekerjannya, hal ini masuk dalam ranah kefektifan individu, hanya saja individu faktanya di dalam organisasi jarang bekerja sendirian melainkan bekerja sama dengan orang lain (kelompok). Jadi, selain pandangan keefektifan individu, terdapat pula pandangan keefektifan dari segi kelompok.

Carron dan Brawley (dalam Sanchez \& Yurrebaso, 2009) mengungkapkan bahwa kohesivitas kelompok telah dianggap sebagai sebagai penentu keberhasilan kinerja dan efektivitas suatu kelompok, hal tersebut diperkuat oleh pendapat yang telah dilakukan oleh Forsyth (dalam Sanchez \& Yurrebaso, 2009) yang memandang bahwa kohesivitas dianalogikan sebagai lem yang merekatkan suatu kelompok, dengan demikian, kohesivitas sebagai daya pengikat bagi suatu kelompok dan sebagai tolok ukur anggota seberapa kuat keinginan mereka untuk berada dalam kelompok tersebut.

Food and Baverage Product atau disingkat menjadi $F \&$ B Product merupakan salah satu divisi terpenting dalam binis perhotelan terutama pada hotel $\mathrm{X}$ yang merupakan salah satu hotel bintang lima diYogyakarta. Food and Baverage Product adalah suatu divisi yang bertanggung jawab atas pusat kegiatan proses bahan baku makanan di hotel, pusat kegiatan pengolahan makanan, pusat kegiatan masak-memasak makanan di hotel, tempat menghasilkan resep yang baku suatu hidangan di hotel, alat pengukur reputasi dan image hotel melalui pengolahan makanan, sehingga bisnis perusahaan berjalan lancar dan dapat menunjang pencapaian sasaran dan target perusahaan, secara aman, efektif dan efisien serta dapat dipertanggungjawabkan. Oleh karena itu, efektivitas dan kohesivitaskelompok pada divisi ini sangat dibutuhkan oleh perusahaan.

Berdasarkan hasil wawancara awal yang peneliti lakukan pada Assistant chef pastry Hotel X, dan executive chef, peneliti mendapatkan beberapa informasi yang terkait dengan kohesivitas kelompok yaitu rasa kepemilikan atau perasaan menjadi bagian dari kelompok di dalam divisi food and beverage product mengindikasikan adanya permasalahan dan hambatan. Permasalahan pertama yang diutarakan dan dialami oleh YA yang saat ini menjabat sebagai assistant pastry chef, YA yang sebelumnya menjabat sebagai pastry chef harus merelakan jabatannya turun menjadi assistant pastry chef, dikarenakan kurang optimal dalam menjalankan tugas sebagai supervisi, misalkan kurang tegas dalam menjalankan tugas sebagai pemimpin serta menurunnya kinerja YA sebagai pastry chef. Setelah dilakukan wawancara lebih mendalam, peneliti memperoleh informasi bahwa yang mengakibatkan menurunnya kinerja YA dikarenakan YA kurang memiliki rasa aman dalam divisinya, yaitu adanya ancaman yang sering muncul dari bawahannya yang sulit diatur yang pada akhirnya membuat YA merasa tidak nyaman bekerja dalam divisi dan kurang optimal dalam menjalankan pekerjaannya. Permasalahan yang hampir sama diutarakan oleh SP selaku demy chef bahwa karyawan dalam divisi food and beverage product belum mampu membuat rekan kerja satu sama lain merasa aman dan optimal dalam menjalankan pekerjaan, seperti kasus yang diceritakan oleh SP bahwa ada salah seorang karyawan yang mengundurkan diri sebelum habis kontrak karena merasa tidak nyaman dengan perlakuan dan perkataan anggota divisi yang lain. 
Selain itu PB selaku yang dan beberapa karyawan yang kurang menghargai yang termasuk dalam mendapatkan informasi bahwa pada divisi $F \& B$ product masih ada beberapa karyawan yang kurang peduli baik dengan pekerjaannya maupun dengan masalah dalam divisi, misalkan ketika Executive chef di food and beverage product memaparkan bahwa, apabilaperusahaan sedang dalam keadaan occupancy yang tinggi, para anggota divisi akan saling melemparkan pekerjaan satu sama lain antar section,sehingga mengakibatkan suasana dalam divisi food and beverage productmenjadi kurang nyaman bagi para anggotanya. Hal lain yang dijelaskan oleh executive chef yaitu ada beberapa karyawan yang kurang memiliki kesadaran untuk menyapa terlebih dahulu, walaupun dengan para supervisor dan hampir 50\% presentase dari anggota divisi merasa percaya diri dengan rutinitas yang telah dilakukan, sehingga membuat para anggota tersebut kurang menunjukkan keterbukaan terhadap masukan yang diberikan. Mengingat kebersamaan dan kepedulian terhadap kelompok yang baik sangat dibutuhkan oleh karyawan Hotel X, apabila hal ini terjadi terus menerus maka akan mengakibatkan terjadinya suatu permasalahan dalam lingkungan kerja terutama dalam pelaksanaan kerja serta menurunya kohesivitas yang dimiliki oleh divisi $F \& B$ Product.

Penelitian ini bertujuan untuk mengetahui bahwa dengan pelatihan komunikasi interpersonal diharapkan dapat meningkatkan kohesivitas kelompok karyawan divisi Food and Beverage Product Hotel X Yogyakarta. Manfaat teoritis yang didapat dari penelitian ini adalah memperkaya khasanah ilmu pengetahuan bidang psikologi pada umumnya, dan psikologi industri dan organisasi pada khususnya. Manfaat praktis yang didapat dari penelitian ini adalah Memberikan rekomendasi pentingnya pelatihan komunikasi interpersonal untuk meningkatkan kohesivitas kelompok untuk Hotel X Yogyakarta khususnya pada divisi Food and beverage product.

\section{METODE}

Desain eksperimen yang digunakan pada penelitian ini adalah eksperimen kuasi.Eksperimen kuasi merupakan eksperimen yang dilakukan tanpa randomisasi (Shadish, Cook, dan Campbell, 2002). Eksperimen kuasi ini digunakan untuk pertimbangan praktis dan etis. Walaupun dilakukan tanpa proses randomisasi, eksperimen kuasi tetap melakukan kontrol terhadap beberapa variabel noneksperimental dan menggunakan kelompok kontrol sebagai kelompok komparatif untuk memahami efek perlakuan (Latipun, 2002). Berikut tabel yang dapat menjelaskan desain penelitian sebagai berikut:

\begin{tabular}{|cccc|}
\hline (KE) R O1 & X & O2 & O3 \\
\hline$($ KK) R O1 & & O2 & O3 \\
\hline
\end{tabular}

Gambar 1. Rancangan untreated control group design with pretest and posttest

(Sumber: Shadish, Cook \& Campbel, 2002) 
Keterangan :

$\mathrm{KE}=$ kelompok eksperimen

$\mathrm{KK}=$ kelompok kontrol

$\mathrm{R}=\mathrm{Random}$

$\mathrm{O} 1$ = pengukuran sebelum diberi perlakuan

$\mathrm{O} 2$ = pengukuran setelah diberi perlakuan

$\mathrm{O} 3$ = pengukuran 1 bulan setelah diberi perlakuan

$\mathrm{X}=$ perlakuan

Subjek penelitian ini adalah karyawan hotel $\mathrm{x}$ Yogyakarta pada divisi $F \& B$ productberjumlah 32orang. Subjek dibagi menjadi dua kelompok yaitu kelompok eksperimen dan kelompok kontrol.Dengan karakteristik, memiliki kohesivitas kohesivitas dalam kategori sedang dan rendah setelah mengisi skala kohesivitas kelompok sebagai data pre-test subjek, berusia minimal 20 tahun, berjenis kelamin lakilaki dan perempuan, serta tingkat pendidikan minimal Sekolah Menengah Atas/Kejuruan hingga Strata Satu (S1).

Skala yang digunakan dalam penelitian ini adalah skala kohesivitas kelompok.Skala kohesivitas kelompok bertujuan untuk mengukur kohesivitas kelompok pada karyawan hotel x Yogyakarta. Skala ini dirancang berdasarkan deskripsi perilaku spesifik yang diungkapkan oleh Widmeyer (Paola \& Carless, 2000) dalam 4 (empat) dimensi yaitu, yaitu integrasi kelompok tugas, integrasi kelompok sosial, ketertarikan individu kepada kelompok tugas, dan ketertarikan individu kepada kelompok sosial.

Analisis data yang digunakan dalam penelitian ini adalah analisis non parametric karena jumlah sampelnya kecil (Ghozali dan Castellan, 2002). Pengujian perbedaan kohesivitas kelompok sebelum dan sesudah diberi pelatihan komunikasi interpersonal untuk antar kelompok menggunakan tekhnik analisis Wilcoxon $T$ - Test yaitu untuk mengetahui signifikansi perbedaan rata-rata $(\mu)$ antara kelompok sampel yang satu dengan yang lain (Sugiyono, 2007), analisis ini dapat dilakukan dengan bantuan program SPSS 16 For Windows.

\section{HASIL}

Pengujian hipotesis dalam penelitian ini menggunakan analisis Wilcoxon t-Test Analisis ini digunakan untuk mengetahui perbedaan pengaruh pelatihan komunikasi interpersonal terhadap peningkatan kohesivitas kelompok karyawan food and beverage product di Hotel X sebelum dan setelah diberikan perlakuan.

\section{1) Pretest, Posttest dan Follow Up kelompok eksperimen dan kelompok kontrol}

Analisis pertama dilakukan dengan menguji perbedaan pretest, posttest dan follow up pada kelompok eksperimen dan kelompok control. Pengujian dilakukan dengan menggunakan One Way-Kruskall Wallis. Hasil perhitungan uji beda kedua rata-rata adalah sebagai berikut: 
Tabel 1.

Uji Beda Pretest, Posttest dan Follow Up Kelompok Eksperimen dan Kelompok Kontrol

\begin{tabular}{lccc}
\hline \multicolumn{1}{c}{ Uji Beda } & Asymp Sig & Chi Square & Keterangan \\
\hline Pretest & 0,663 & 0,190 & Tidak Signifikan \\
Posttest & 0,009 & 6,795 & Signifikan \\
Follow Up & 0,001 & 11,804 & Signifikan \\
\hline
\end{tabular}

Hasil Analisis uji One Way- Kruskall Wallis pada kelompok eksperimen dan kelompok control untuk uji beda pretest diperoleh Chi square =0,190 dan skor Asymp Sig> 0,05. Berdasarkan analisis uji One Way-Kruskall Wallis tersebut diketahui bahwa tidak ada perbedaan yang signifikan kohesivitas kelompok pada kelompok eksperimen dan control sebelum diadakan pelatihan komunikasi interpersonal. Artinya kohesivitas kelompok pada kelompok eksperimen dan control sebelum pelatihan komunikasi interpersonal tidak ada perbedaan.

Hasil Analisis uji One Way- Kruskall Wallis pada kelompok eksperimen dan kelompok kontrol untuk uji beda posttest diperoleh Chi square = 6,795 dan skor Asymp Sig< 0,05. Berdasarkan analisis uji One Way- Kruskall Wallis tersebut diketahui bahwa ada perbedaan yang signifikan kohesivitas kelompok pada kelompok eksperimen dan control setelah diadakan pelatihan komunikasi interpersonal. Artinya kohesivitas kelompok pada kelompok eksperimen dan control setelah pelatihan komunikasi interpersonal ada perbedaan.

Hasil Analisis uji One Way- Kruskall Wallis pada kelompok eksperimen dan kelompok control untuk uji beda follow up diperoleh Chi square $=11,804$ dan skor Asymp Sig< 0,05 . Berdasarkan analisis uji One Way-Kruskall Wallis tersebut diketahui bahwa ada perbedaan yang signifikan kohesivitas kelompok pada kelompok eksperimen dan control dalam jangka panjang setelah diadakan pelatihan komunikasi interpersonal. Artinya kohesivitas kelompok pada kelompok eksperimen dan control dalam jangka panjang komunikasi interpersonal ada perbedaan.

2) Uji Beda Pretest, Posttest, dan Follow Up pada masing-masing kelompok

Analisis kedua dilakukan dengan menguji perbedaan Pretest, Posttest, dan Follow Up pada masing-masing kelompok, yaitu eksperimen dan kelompok control. Pengujian dilakukan dengan menggunakan Friedman Test Hasil perhitungan uji beda kedua ratarata adalah sebagai berikut: 
Tabel 2.

Uji Beda Pretest, Posttest, dan Follow Up Kelompok Eksperimen dan Kelompok Kontrol

\begin{tabular}{lccc}
\hline \multicolumn{1}{c}{ Kelompok } & Asymp Sig & Chi Square & Keterangan \\
\hline Eksperimen & 0,000 & 5,200 & Signifkan \\
Kontrol & 0,074 & 25,581 & Tidak Signifikan \\
\hline
\end{tabular}

Hasil analisis uji Friedman Test skorPretest, Posttest, dan Follow Up pada kelompok kontrol diperoleh Chi Square $=5,200$ dan skor $p=>0,01$. Berdasarkan analisis uji Friedman Test tersebut diketahui bahwa tidak ada perbedaan yang sangat signifikan kohesivitas kelompok pada kelompok eksperimen baik dalam Friedman Test untuk Pretest, Posttest, dan Follow Up. Hal tersebut dapat diartikan bahwa kohesivitas kelompok pada kelompok control dalam keadaan Pretest, Posttest, dan Follow Up tidak ada peningkatan.

Hasil analisis uji Friedman Test skorPretest, Posttest, dan Follow Up pada kelompok eksperimen diperoleh Chi Square $=25,581$ dan skor $p=<0,01$. Berdasarkan analisis uji Friedman Test tersebut diketahui bahwa ada perbedaan yang sangat signifikan kohesivitas kelompok pada kelompok eksperimen baik dalam Friedman Test untuk Pretest, Posttest, dan Follow Up. Hal tersebut dapat diartikan bahwa kohesivitas kelompok pada kelompok eksperimen dalam keadaan Pretest, Posttest, dan Follow Up ada peningkatan setelah diberikan pelatihan komunikasi interpersonal.

3) Uji Beda Pretest-Posttest dan Posttest-Follow Up pada kelompok eksperimen.

Analisis ketiga dilakukan dengan menguji perbedaan Pretest-Posttest dan PosttestFollow Up pada kelompok eksperimen. Pengujian dilakukan dengan menggunakan Post Hoc Wilcoxon T-Test. Hasil perhitungan uji beda rata-rata adalah sebagai berikut:

Tabel 3.

Uji Beda Pretest-Posttest dan Posttest-Follow Up pada kelompok eksperimen

\begin{tabular}{lccc}
\hline \multicolumn{1}{c}{ Kelompok } & Asymp Sig & $\boldsymbol{Z}$ & Keterangan \\
\hline Pretest- Posttest & 0,000 & $-3,519$ & Signifkan \\
Posttest- Folow Up & 0,026 & $-2,234$ & Signifkan \\
\hline
\end{tabular}

Hasil analisis uji Post Hoc Wilcoxon T-Test skor Prettest- Posttest pada kelompok eksperimen diperoleh $\mathrm{Z}=-3,519$ skor Asymp Sig $=<0,01$. Berdasarkan analisis uji Post Hoc Wilcoxon T-Test tersebut diketahui bahwa ada perbedaan yang signifikan kohesivitas kelompok pada kelompok eksperimen pada saat pretest- posttest.Artinya kohesivitas kelompok pada kelompok eksperimen mengalami peningkatan setelah diberikan pelatihan komunikasi interpersonal. 
Hasil analisis uji Post Hoc Wilcoxon T-Test skor Posttest- Follow Up pada kelompok eksperimen diperoleh $\mathrm{Z}=-2,234$ skor Asymp Sig $=<0,01$. Berdasarkan analisis uji Post Hoc Wilcoxon T-Test tersebut diketahui bahwa ada perbedaan yang signifikan kohesivitas kelompok pada kelompok eksperimen pada saat posttest-follow up. Artinya kohesivitas kelompok pada kelompok eksperimen tetap mengalami peningkatan dalam jangka panjang setelah diberikan pelatihan komunikasi interpersonal.

4) Pretest, Posttest dan Follow Up Kelompok Eksperimen

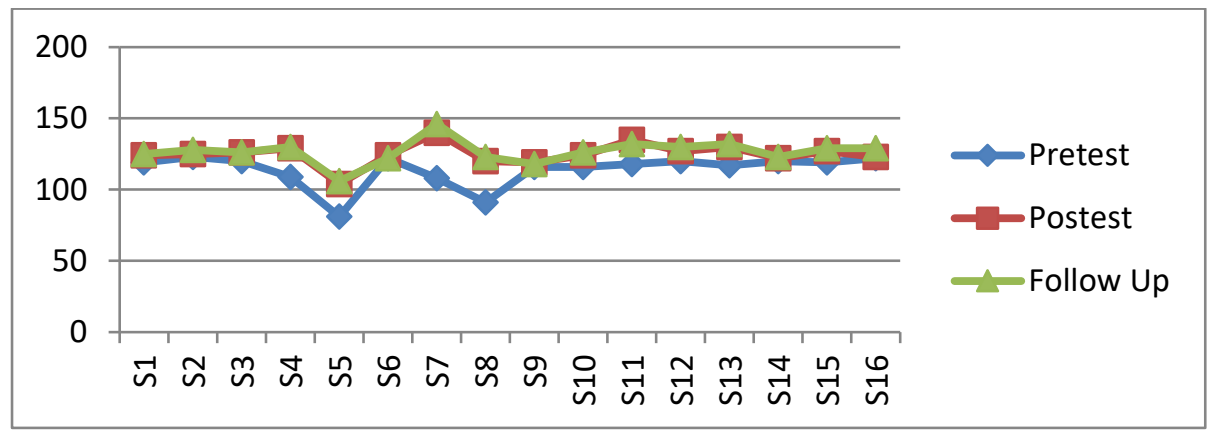

Gambar 2. Grafik Nilai Subjek Pretest-Postest-Follow UpKelompok Eksperimen Skala Kohesivitas Kelompok

Dari grafik diatas dapat dilihat perubahan kohesivitas kelompok pada masing-masing subjek kelompok eksperimen pada saat pretest dan posttest.Dimana terjadi peningkatan nilai kohesivitas kelompok yang signifikan antara dan sebelum dan sesudah perlakuan diberikan kepada kelompok eksperimen, kemudian pada saat posttest dan follow up tidak ada perbedaan nilai kohesivitas kelompok yang signifikan dala kelompok eksperimen, artinya setelah dua bulan pelatihan, kohesivitas kelompok para peserta masih konsisten.

\section{DISKUSI}

Permasalahan utama yang diteliti dalam penelitian ini adalah apakah pelatihan komunikasi interpersonal memiliki pengaruh terhadap meningkatnya kohesivitas kelompok karyawan. Hipotesis yang diajukan dalam penelitian ini adalah terdapat pengaruh positif pelatihan komunikasi interpersonal dalam upaya peningkatan kohesivitas kelompok karyawan Hotel X. Dimana diharapkan setelah dilakukannya proses pelatihan pada karyawan tersebut diharapkan hasil berupa adanya peningkatan kohesivitas terhadap karyawan.

Berdasarkan analisis data pretest dan posttest yang menggunakan uji non-parametrik Wilcoxon $t$-tes dengan melakukan perhitungan skor kohesivitas kelompok antara kelompok eksperimen dan kelompok kontrol dengan melihat nilai mean masing-masing kelompok. Hasil Analisis uji One Way-Kruskall Wallis pada kelompok eksperimen dan kelompok control untuk uji beda pretest diperoleh Chi square $=0,190$ dan skor Asymp Sig> 0,05. Berdasarkan analisis uji One Way-Kruskall Wallis tersebut diketahui bahwa tidak ada perbedaan yang signifikan kohesivitas kelompok pada kelompok eksperimen dan kontrol sebelum diadakan pelatihan komunikasi interpersonal. Artinya kohesivitas 
kelompok pada kelompok eksperimen dan kontrol sebelum pelatihan komunikasi interpersonal tidak ada perbedaan.

Hasil Analisis uji One Way- Kruskall Wallis pada kelompok eksperimen dan kelompok kontrol untuk uji beda posttest diperoleh Chi square = 6,795 dan skor Asymp Sig< 0,05. Berdasarkan analisis uji One Way- Kruskall Wallis tersebut diketahui bahwa ada perbedaan yang signifikan kohesivitas kelompok pada kelompok eksperimen dan control setelah diadakan pelatihan komunikasi interpersonal. Artinya kohesivitas kelompok pada kelompok eksperimen dan kontrol setelah pelatihan komunikasi interpersonal ada perbedaan.

Hasil Analisis uji One Way- Kruskall Wallis pada kelompok eksperimen dan kelompok kontrol untuk uji beda follow up diperoleh Chi square = 11,804 dan skor Asymp Sig < 0,05. Berdasarkan analisis uji One Way-Kruskall Wallis tersebut diketahui bahwa ada perbedaan yang signifikan kohesivitas kelompok pada kelompok eksperimen dan kontrol dalam jangka panjang setelah diadakan pelatihan komunikasi interpersonal. Artinya kohesivitas kelompok pada kelompok eksperimen dan kontrol dalam jangka panjang komunikasi interpersonal ada perbedaan. Hal ini menunjukkan bahwa hipotesis awal yang berbunyi ada pengaruh positif pemberian pelatihan komunikasi interpersonal terhadap peningkatan kohesivitas kelompok karyawan diterima.

Tujuan diadakannya pelatihan komunikasi interpersonal adalah untuk membantu anggota tim agar mampu mengenal anggota tim satu sama lain, mengurangi konflik antar sesama anggota tim dan meningkatkan kekompakan serta kesolidan dalam tim kerja dalam mencapai tujuan perusahaan yang akhirnya akan memberikan profit pada perusahan. Materi pembentukan tim yang diberikan membantu peserta untuk mengoptimalkan kekuatan tim dalam menghadapi tantangan-tantangan yang terjadi, mampu mengatasi tantangan secara tim, mengurangi konflik antar sesama anggota tim dan mampu meninngkatkan kohesivitas tim untuk bangkit bersama.

Kohesivitas diartikan sebagai rasa kepemilikan atau perasaan menjadi bagian dari kelompok dan tingkat moril dan antusiasme untuk menjadi bagian dari suatu kelompok (Dyaram dan Kamalanbhan, 2005). Kohesivitas sebagai suatu daya tarik atau kekuatan yang memaksa para anggotanya untuk tetap berada didalam kelompok.Kekuatan ini lebih besar daripada kekuatan yang menarik para anggotanya keluar dari kelompok (Davis dan Newstrom, 1992). Sehingga dapat dipahami apabila kohesivitas diartikan sebagai daya tarik menarik anggota kelompok satu dengan yang lain dan keinginan mereka untuk menjadi bagian dari kelompok.

Widmeyer, Brawley, dan Carron dalam (Paola dan Carless, 2000) Kohesivitas tugas merupakan tingkat motivasi dalam mencapai tujuan organisasi. Sebuah kelompok dengan kohesi tugas yang tinggi terdiri dari anggota yang berbagi dalam mencapai tujuan bersama dan termotivasi untuk mengkoordinasi upaya agar mencapai tujuan tersebut.Serupa dengan ini, kekompakan sosial mengacu pada motivasi untuk mengembangkan dan memelihara hubungan sosial dalam kelompok. Kekompakan sosial terlihat sejauh mana anggota kelompok saling menyukai, memilih untuk menghabiskan waktu secara bersama, dan merasa dekat secara emosional satu dengan yang lain. 
Berdasarkan dari berbagai hasil penelitian diketahui bahwa pelatihan komunikasi interpersonal Komunikasi merupakan elemen penting dalam organisasi untuk membangun hubungan antara anggota organisasi dan pihak-pihak lain untuk mencapai kerjasama yang diperlukan untuk pencapaian tujuan.Gibson dan Hodgetts (dalam Siburian, 2013) berpendapat bahwa komunikasi adalah transfer makna atau pemahamandari pengirim ke penerima, yang meliputi pengirim, penerima, dan keberhasilan pengiriman makna.Scott dan Mitchell (dalam Siburian, 2013) berpendapat bahwa komunikasi memiliki empat fungsi utama dalam sebuah organisasiyaitu: fungsi kontrol, motivasi, ekspresi emosional, dan informasi. Komunikasi adalah pertukaranpesan verbal dan non-verbal antara pengirim dan penerima pesan untuk mengubah perilaku. Gibson, Ivancevich, dan Donnelly (1996) menyatakankomunikasi adalah proses penyampaian atau menerima pesan dari satu orang ke orang lain, baiklangsung atau tidak langsung, secara tertulis, bahasa verbal dan non-verbal. Selanjutnya, Barelson (dalam Siburian, 2013) menyatakankomunikasi sebagai penyampaian informasi, gagasan, emosi, dan keterampilan lainnya melalui simbolsimbol, kata-kata, gambar,angka, grafik, dan tanda lainnya. Berdasarkan pernyataan ini dapat disimpulkan bahwa manusia pada dasarnyaberkomunikasi dengan tujuan untuk menjadi tahu, membuat penilaian input dan output sesuatu.

Hasil penelitian menunjukkan bahwa hipotesa diterima. Penelitian berjalan dengan baik dan memiliki manfaat terhadap subjek penelitian. Pelatihan yang dilakukan mampu memberikan pengetahuan kepada subjek mengenai materi komunikasi interpersonal yang selama ini masih belum diketahui secara jelas. Hal ini bisa terlihat dari hasil evaluasi pengetahuan berupa tes kognitif yang dilakukan sebelum dan sesudah pelatihan. Hasil skor tes kognitif meningkat dari sebelum pelatihan 6,25\% subjek dalam kategori pengetahuan tinggi, 87,5\% subjek dalam kategori pengetahuan sedang, dan $6,25 \%$ subjek dalam kategori pengetahuan rendah. Setelah dilakukan pelatihan presentase meningkat $62,5 \%$ subjek dalam kategori pengetahuan tinggi dan 37,5\% subjek dalam kategori sedang. Kategorisasi diatas dapat terlihat bahwa tidak ada subjek yang berada pada kategori rendah setelah dilakukan pelatihan.

Gambaran diatas yang telah diterapkan dalam pengetahuan dan perilaku-perilaku baru pada pelatihan komunikasi interpersonal ini mendikasikan bahwa subjek eksperimen dapat mempraktekan dalam kehidupan sehari-hari terutama dalam dunia kerja. Secara keseluruhan dalam evaluasi reaksi yang telah dilakukan sebanyak $81,25 \%$ subjek pelatihan merasa sangat puas terhadap pelatihan komunikasi interpersonal. Hal ini diungkapkan oleh peserta pelatihan S14yang mengungkapkan bahwa pelatihan komunikasi interpersonal ini sangat baik bagi kinerja kedepan juga pada kehidupan peserta. Peserta merasa lebih positif setelah mengikuti training. Peserta S16 Apa yang disampaikan ditraining ini sangat berbeda dengan kondisi didepartment tempat peserta bekerja, sehingga dengan adanya pelatihan ini sangat membantu memperbaiki kondisi tersebut.

Pelatihan komunikasi interpersonal yang telah dilaksanakan terbukti mampu memberikan hasil yang sesuai dalam meningkatkan kohesivitas kelompok karyawan.Didukung dengan hasil analisa kuantitatif dan hasil wawancara HR Coordinator.Hasil wawancara dengan HR Coordinator Hotel X juga mendukung hasil penelitian ini yaitu terdapat perubahan yang signifikan pada kohesivitas 
karyawan.Perubahan-perubahan pada kohesivitas karyawan dilihat dari karyawan sudah mulai dapat bekerjasama dengan baik baik satu departemen maupun antar departmen.Sehingga ketika ada acara dan grup tamu hotel semakin mudah dalam melakukan koordinasi baik antara Food \& Beverage, House Keeping dan Front Office.Keluhan yang diterima pihak hotel oleh tamu pun berkurang. Dengan adanya pelatihan ini masing-masing anggota tim dapat mengenal satu sama lain dan mengetahui masing-masing karakter tim. Karyawan pun terlihat semakin solid dan menyatu sama lain.

\section{SIMPULAN DAN IMPLIKASI}

Berdasarkan analisis data dan pembahasan yang dilakukan dalam penelitian ini, maka dapat disimpulkan bahwa pelatihan komunikasi interpersonal dapat meningkatkan kohesivitas kelompok karyawan Hotel X khususnya karyawan yang menjadi subjek padakelompok eksperimen. Sedangkan pada kelompok kontrol yang tidak diberikan perlakuan tidak terjadi peningkatan terhadap skor kohesivitas kelompok dan bahkan cenderung mengalami penurunan. Hal ini membuktikan bahwa, bahwa pelatihan komunikasi interpersonal dapat meningkatkan kohesivitas kelompok karyawan Hotel X dan dapat dijadikan sebagai salah satu alternative intervensi yang diberikan untuk dapat meningkatkan kohesivitas kelompok karyawan

Beberapa hal yang perlu disempurnakan agar pelatihan komunikasi interpersonal pada penelitian-penelitian selanjutnya dapat memberikan hasil yang lebih optimal, antara lain sebagai berikut:

Bagi Organisasi: Perusahaan diharapkan ikut memfasilitasi karyawan dalam melakukan perubahan setelah pelatihan berlangsung; Dukungan dari Top Management sangat diperlukan untuk menciptakan perubahan yang diinginkan; Hendaknya pelatihan karyawan diberikan waktu khusus untuk pelatihan dan tidak menggunakan jam kerja. Hal tersebut akan mendukung fokus karyawan dalam mengikuti pelatihan.

Bagi peneliti selanjutnya: Penelitian sejenis sebaiknya juga dilakukan pada perusahaan lain yang berbeda jenis dengan yang peneliti lakukan, karena penelitian dengan tipe perusahaan yang berbeda belum tentu memperoleh hasil yang sama; Penelitian sejenis sebaiknya dapat menggunakan metode lain seperti workshop dan outbound yang dapat dilakukan dilapangan luas agar lebih maksimal; Penelitian sejenis lainya sebaiknya dilakukan dengan pemberian perlakuan yang berbeda, tidak hanya berupa pelatihan dengan memberikan teori saja tetapi juga pelatihan yang bersifat aktualisasi sehingga perubahan yang diinginkan dapat terjadi; Peneliti selanjutnya perlu mengupayakan agar semua pihak manajemen ikut terlibat dalam pelatihan agar hasil penelitian dapat lebih optimal sesuai yang diinginkan; Peneliti selanjutnya hendaknya melakukan evaluasi sikap atau perilaku agar dapat mengetahui perubahan perilaku peserta pelatihan setelah pelatihan dilaksanakan; Dapat memfokuskan dan menggunakan teori psikologi islami guna pengembangan psikologi islam. 


\section{REFERENSI}

Ancok, D. (2002). Outbound Management Training: Aplikasi Ilmu Perilaku dalam Pengembangan Sumber Daya Manusia. Yogyakarta: UII Press.

Bangun, W. (2012).Manajemen Sumber Daya Manusia. Erlangga; Jakarta.

Book, C.L. (1980).Human Communication-Principles, Contexts, and Skills. New York: St. Martin'sPress, Inc.

Carron, A.V., Widmeyer, W.N., \& Brawley, N.D. (1985).The Development of An Instrument to Assess Cohesion in Sport Teams: The Group Environment Questionnare. Journal Sport Psychology 7, 244-266.

Cummings, T.G. \& Worley, C.G. (2005).Organization development and Change. 6th Ed. South-Western: College Publishing.

De Vito, J. (1995). The Interpersonal Communication Book. Fourth Edition, New York : Harper and Row Edition.

De Vito, J. (1997). Komunikasi Antar Manusia. Jakarta : Professional Books.

Forsyth, D.R. (2006).Group Dynamics 4th Edition. United States of America: Thomson Learning Inc.

Grant K., David W.C., George S.L., \& William C.M. (2001). The Role of Satisfaction with Territory Design on the Motivation, Attitudes, and Work Outcomes of Salespeople.Journal of the Academy of Marketing Sciene. 29 (2), 165-178.

Gibson, Ivancevich., Donnelly., \& Konopaske. (2003). Organizational behavior structure process.Fourteenth edition McGraw -Hill Higher Education.

Goble, F.G. (2000).The Third Force, The Psychology of Abraham Maslow (Terjemahan Supratiknya, A.).Yogyakarta: Kanisius.

Gordon, J.R., Mondy, R., Sharplin, A., \& Preumax, S.R. (1990).Management and Organization Behaviour.Massachusetts : Simon\& Schuster.

Ghozali, I \& Castellan, N.J. (2002). Statistic Nonparametrik: Teori Aplikasi dengan Program Spss. Semarang: Badan Penerbit Universitas Diponegoro

Hadipranata, A.F. (1995). Pengaruh Kelompok Kecil Kerja Kompak Terhadap Performansi Kerja Karyawan di Surabaya. Jurnal Psikologi, 2,49-56.

Hardjana M. Agus. (2001). Training SDM yang Efektif. Yogyakarta: Kanisius.

Johnson, D.W (1981). Reaching Out. Interpersonal effectiveness and selfActualization.Englewood Cliffs : Prentice Hall.

Kirkpatrick, D. (1994) Evaluating Training Programs - The Four Level. Berret-Koehler Publisher.Inc. 
Latipun.(2009). Psikologi Eksperimen Edisi Pertama. Malang: UMM Press.

Levi, D. (2001). Group Dynamic for Teams. London: Sage Publications.

Lunandi, A.G. (1994). Komunikasi Mengenai : Meningkatkan Efektivitas Komunikasi antar Pribadi. Kanisius: Yogyakarta.

Luthans, F. (2006). Perilaku Organisasi (Organizational Behavior 10th edition). Yogyakarta: Andi Offset.

Mathew T, Shetty A, Shetty C, Narasinham D, Shetty S \& Hedge N.M. (2015). Comparison of communication skills between undergraduate dental students with and without prior training in effective communication.Nitte university journal of health science. 5 (2), 8-11.

Matin, Jandhagi, Karimi, \& Hamidizadeh.(2010). Relationship between interpersonal communication skills and organization commitment.European Journal of Social Sciences. 13 (3), 387-398.

Marwansyah. (2012). Manajemen Sumber Daya Manusia, Edisi Kedua. Bandung: Alfabeta.

Munandar. (2001). Psikologi Industri dan Organisasi.Jakarta : Universitas Indonesia Press.

Muthiane C.M, Rintaugu E.G, \& Mwisukha A. (2015). The relationship between team cohesion and performance in basketball league in Kenya.International journal of applied psychology. 5 (4), 85-90.

Noe. A. Raymond. (2010). Employee Training And Development. Mc-Graw-Hill Irwin: The Ohio State University

Panuju.R. (2001). Komunikasi Organisasi dari Konseptual-Teoritis ke Empirik.Yogyakarta : Pustaka Pelajar.

Paola, C.D., \& Carless, S.A. (2000).The Measurement of Cohesion in Work Teams.Small Group Research; 31 (71).

Poerwandari, K. (2005). Pendekatan Kualitatif untuk Penelitian Perilaku Manusia.Lembaga Pengembangan Sarana Pengukuran dan Pendidikan Psikologi Fakultas Psikologi Univeritas Indonesia.

Raco, J.R. (2010). Metode Penelitian Kualitatif: Jenis, Karakteristik, dan Keunggulannya. Jakarta : PT. Gramedia Widiasarana Indonesia.

Rakhmat, J. (2005). Psikologi Komunikasi. Edisi Revisi. Bandung: PT. Remaja Rosdakarya.

Robbins, S.P. (2002). Prinsip-prinsip Perilaku Organisasi. Jakarta: Erlangga.

Sandez, J.C \& Yurrebaso, A. (2009). Group Cohesion: Relationship with work team culture. Psichothama. 21 (1), 97-104. 
Sears, D. O., Freedman, J. L., \& Peplau, L. A. (1999). Social Psychology 5th Edition (Alih Bahasa Andryanto, M. dan Soekrisno, S.). Jakarta: Erlangga.

Shadish, W.R., Cook, T.D. \& Campbell, D.T. (2002).Experimental And QuasiExperimental Designs For Generalized Causal Inference. New York: Houghton Mifflin Company.

Siburian. (2013). The effect of interpersonal communication, organizational culture, job satisfaction, and achievement motivation to organizational commitment of state high school teacher in the district Humbang Husundutan, North Sumatera, Indonesia. International Journal of Humanities and Social Science. 3 (13), 247264.

Simmamora, H. (2006). Manajemen Sumber Daya Manusia Edisi 2. Yogyakarta: STIE YKPN.

Sugiyono.(2007). Statistik Non Parametris untuk Penelitian. Bandung: Alfabeta.

Taylor, S.E., Peplau, L.A., \& Sears, D.O. (2009).Social Psychology 12th Edition. (Alih Bahasa TriWibowo B.S.). Jakarta: Prenada Media Group.

Wood, T.J. (2013). Komunikasi Interpersonal, Interaksi Keseharian. Jakarta; Salemba Humanika. 